\title{
Sylvan's Bottle and other problems
}

\author{
Diane Proudfoot \\ University of Canterbury \\ New Zealand
}

\begin{abstract}
According to Richard Routley, a comprehensive theory of fiction is impossible, since almost anything is in principle imaginable. In my view, Routley is right: for any purported logic of fiction, there will be actual or imaginable fictions that successfully counterexample the logic. Using the example of 'impossible' fictions, I test this claim against theories proposed by Routley's Meinongian contemporaries and also by Routley himself (for what he called 'esoteric' works of fiction) and his 21st century heirs. I argue that the phenomenon of impossible fictions challenges even today's modal Meinongians.
\end{abstract}

\section{Routley's rules for the semantics of fiction}

According to Richard Routley, 'any properly comprehensive theory of objects ... is obliged to supply a theory of fictions' (1980, p. 538). Nevertheless, fictions, he said, 'provide a severe testing ground for logical and semantical theories' and 'have regularly revealed serious weaknesses in each new theory proposed' (ibid., p. 537). The severity of the test is due to certain characteristics of fiction noted by Routley, which I shall formulate as a set of three rules:

R1. '[T]he author of a work of fiction can try to set down whatever he imagines; and the free range of imagination is virtually unlimited.' '[An author has the] freedom to create whatever he will within the bounds of his art' (Routley 1979, pp. 6, 8)

R2. '[T]here are fictional worlds in which any given logical truth (or theorem) fails to hold or is violated.' (ibid., p. 7)

R3. '[T]he logic of a world associated with a work of fiction may be any logic that the author chooses to impose.' (ibid., p. 10)

R1-3 lead to further claims by Routley about fiction. From R1 we can derive:

C1. '[T]he worlds of fiction may be very bizarre and deviate enormously from the actual world' $(1979$, p. 6)

Australasian Journal of Logic (15:2) 2018, Article no. 2.4 
and

C2. 'There can thus be no restriction of the worlds required for a semantical analysis of works of fiction, of fictional discourse, to the possible worlds of most modern semantics' (ibid., p. 6)

From R3, we can derive:

C3. 'If an author decides to write an intuitionist or connexivist or nihilist work then he can impose the corresponding logic, and things will occur or be rejected in the world he imagines and describes in accord with the principles of the corresponding logic.' (ibid., p. 10)

In addition, the conjunction of $\mathrm{R} 1$ and $\mathrm{R} 2$ implies:

C4. [The 'free range of imagination' and therefore 'a work of fiction'] is not bounded by laws of nature or even by laws of logic.' (ibid., p. 6)

The above rules and conclusions can be summarized as (what I shall call) Routley's Thesis: 'there is no general uniform logic of fiction' (ibid., p. 10). Routley said, 'In general, each work will have its own internal logic: it is simply that the emerging set of common logical principles will be zero' (ibid., p. 11).

These are wise words. Semantics of fictional discourse typically take their examples from a very few fictions, as the well-worn example of Sherlock Holmes illustrates. However, Conan Doyle's stories are unusual: first-person narratives, where nothing is said by the narrator that he could not quite naturally and easily come to know, where it is axiomatic for Holmes that what seems paradoxical can be explained away, and where nothing is deliberately left open. These stories are very different from the more complex fictions that populate literary canons.

Proponents of Meinongian or noneist theories (i.e., theories positing nonexistent objects, situations, or worlds) frequently argue for their metaphysics on the ground that it provides a semantics of fictional discourse. ${ }^{1}$ This is, they say, one of 'the main motivations for the Meinongian view' (Berto 2013b, p. 90). Impossible fictions (i.e., stories containing or entailing a contradiction) are generally held to provide a particular problem for semanticists of fictional discourse; many of today's modal Meinongians claim that positing nonexistent impossible worlds yields a 'natural' treatment of such fictions (Berto 2013a). In this paper, therefore, my topic is impossible fictions, invented and extant.

In Section 2 I describe (what I shall call) the Counter-examplibility Phenomenon. Section 3 sets up the problem of impossible fictions and why they matter, beginning with David Lewis's account of truth in fiction. Section 4 argues, by means of counterexamples, that the accounts of impossible fictions offered by Routley's most influential Meinongian contemporaries - Terence Parsons and Edward Zalta - fail. Section 5 describes Routley's own theory of fiction and introduces the theories of today's modal Meinongians, of which Graham Priest's is the canonical account. In Sections 6-9 I argue that even Priest's Routley-inspired theory of inconsistent fiction is vulnerable to counterexamples. 


\section{The Counter-examplibility Phenomenon}

An author can make just about anything the case in a fiction. For this reason, counterexamples to semantics of fictional discourse can fairly easily be found, either by considering a wider range of actual fictions than philosophers typically rely on or by thought experiments describing imaginary fictions. This constitutes:

The Counter-examplibility Phenomenon: For any purported semantics of fictional discourse $s$, a fiction $f$ can be constructed that counterexamples $s$.

Every theory aims to avoid counterexamples. In the case of fiction, however, the very nature of the subject-matter ensures that, no matter what semantics is devised, counterexamples will arise.

Yet if counterexamples are so easily generated, can - and should - they not just as easily be ignored $?^{2}$ In metaphysics and ethics there is a dispute over the role of fantastical thought experiments. Critics claim that, faced with such experiments, intuitions 'run awry' and inferences are 'problematic', with the result that 'we cannot extract philosophically interesting conclusions' (Wilkes 1988, pp. 8, 46). In assessing semantics of fictional discourse, however, merely hypothetical fictions count, no matter how fantastical. The fiction-writer is not constrained by metaphysical, biological, or psychological facts about the actual world - facts required to inform thought experiments in other areas of philosophy. If an imaginary fiction is not plausible or compelling or entertaining, that does not rule it out as fiction, but merely as good fiction.

Another reason to minimize the Counter-examplibility Phenomenon (CEP, for short) might be that the use of counterexamples appears to involve an appeal to intuition; several philosophers, including many recently, have questioned the trustworthiness of intuitions in philosophical reasoning. Intuitions, some say, are 'ill-suited to do the work philosophers ask of them', and philosophers who employ intuitions 'can no longer rest comfortably in their armchairs' (Swain, Alexander, and Weinberg 2008, pp. 140, 138). These challenges, however, appear largely irrelevant in the case of fiction. The 'intuition' involved in selecting or imagining counterexamples is no more than understanding what is true according to a story; and this seems a mundane skill above philosophical suspicion - certainly when compared with fathoming the 'meaning' or value of particular fictions, or 'seeing' the truth of some philosophical claim. No appeal to a special faculty or source of evidence is implied. ${ }^{3}$

In any case, Meinongians themselves take compatibility with intuition as a criterion of a satisfactory semantics of fictional discourse. According to Francesco Berto, for example, "the best theory of fiction is the one that resorts to as few paraphrases of our ordinary discourse on such objects as possible'; 'Intuitions can be massaged, but only to some extent', he says (2011, p. 314). The other Meinongians I will address in this paper typically express similar

sentiments. ${ }^{4}$ For consistency's sake, then, they cannot object to the use of intuition in selecting counterexamples.

Australasian Journal of Logic (15:2) 2018 Article no. 2.4 
Invented (rather than actual) fictions might nevertheless have about them the air of smoke and mirrors. ${ }^{5}$ Parsons observed of his semantics of fictional discourse: "if we want to make trouble for the theory, we're going to have to produce stories which have fairly detailed and well-delineated characters; extremely brief and abstract examples just aren't convincing' (1980, p. 198). However, even if Parsons were correct, there is no obstacle in principle to developing as yet schematic counterexamples, including those that I will suggest in this paper. All it takes is literary virtuosity. For example, who would have thought that a delightful novel - Alphabetical Africa - could be written around the conceit of beginning each word in the first chapter with ' $a$ ', in the second chapter with ' $a$ ' or ' $b$ ' (and so on)? ${ }^{6}$

\section{David Lewis and impossible fictions}

Lewis's 1983 paper 'Truth in Fiction' is the canonical application of possible worlds semantics to fiction. His final analysis of the truth-conditions of intra-fictional sentences (i.e. sentences true in the fiction) is designed to accommodate the background of a fiction while being sensitive to the context in which the fiction originated. It is as follows:

A sentence of the form 'In the fiction $f, \phi$ ' is non-vacuously true iff, whenever $w$ is one of the collective belief worlds of the community of origin of $f$, then some world where $f$ is told as known fact and $\phi$ is true differs less from the world $w$, on balance, than does any world where $f$ is told as known fact and $\phi$ is not true. ${ }^{7}$ (Lewis 1983, p. 273)

On 'impossible fictions', Lewis wrote:

Let us call a fiction impossible iff there is no world where it is told as known fact rather than fiction. That might happen in either of two ways. First, the plot might be impossible. Second, a possible plot might imply that there could be nobody in a position to know or tell of the events in question. If a fiction is impossible in the second way, then to tell it as known fact would be to know its truth and tell truly something that implies that its truth could not be known; which is impossible. (ibid., p. 274)

Lewis originally said that, according to his analysis of truth in fiction, 'anything whatever is vacuously true' in a deliberately impossible fiction (ibid., p. 274).

This analysis of truth in impossible fictions is counter-intuitive, however, for example bringing it about that the following are true: all impossible fictions tell the same story, since each contains all truths; truths in such fictions are also falsehoods; and truths in such fictions are trivial, not to be discovered by the reader. Lewis later revised his account of impossible fictions, conceding in a Postscript that it denied the 'distinctive peculiarity' of such fiction (1983, p. 277). Using instead the 'method of union', an impossible fiction can be divided into a number of consistent fragments, and his analysis used to give us what 
is true in each of them: ' $\phi$ is true in the original fiction iff $\phi$ is true in some fragment', Lewis said (ibid., p. 277). In the case of an explicit contradiction $A, \sim A$ (where both $A$ and $\sim A$ are themselves logically possible statements), $\sim A$ will be true according to one fragment and $A$ according to another. However, Lewis said, 'we must not close under implication ... We should not even close under the most obvious and uncontroversial sort of implication: the inference from conjuncts to conjunction' (ibid., pp. 277-8). So it will not be true according to the original fiction that $A \& \sim A$, for $A \& \sim A$ is true in neither fragment. Likewise, without closure there will be no explosion of trivial truths.

I have previously argued that Lewis's revised method does not work well in cases where the original fiction contains a single 'root' responsible for each branch of a contradiction (Proudfoot 2006). This is because no consistent fragment can contain this root. To illustrate the point, we need only consider Lewis's own examples of impossible fictions - 'a fantasy about the troubles of the man who squared the circle' and 'the worst sort of incoherent timetravel story' (1983, p. 275). Applying the method of union to the former, the contradictiongenerating root ' $m$ squares the circle' cannot be included in any consistent fragment of the original fiction, and so will be true according to no fragment. Yet intuitively it is true in the original fiction that $m$ squares the circle. Moreover, since there is no possible world in which a man squares a circle, it comes out true according to every fragment - but counterintuitively - that $m$ did not square the circle.

Many actual fictions have plots that revolve around a contradiction-entailing root. Jasper Fforde's comic novel The Eyre Affair is a recent example. In this novel actual people 'step inside' fictions. This includes Japanese 'tourists' shown round the house of Edward Rochester, the character from Charlotte Brontë's novel Jane Eyre: this is 'the ultimate trip for a Brontë fan', which also helps Rochester to keep a roof over his head ('Country houses are not cheap to run', he says). Correspondingly fictional characters make the 'jump' to the actual world, where they are bade 'Welcome to the twentieth century and reality'. In The Eyre Affair the fictional character Jane Eyre is kidnapped by actual people, who hold her for ransom in the actual world. Interaction between the actual and the fictional - as one character puts it, 'an inexplicable cross-fertilisation between works of fiction and reality' - is essential to the novel. Jane and Rochester are 'PDRs' - 'Persons of Dubious Reality ... Uninvited visitors who have fallen through the grating that divides the real from the written'. 8 That this inconsistency is at the core of The Eyre Affair is emphasized by the image on the front cover, in which the heroine's (three-dimensional) car emerges from a (two-dimensional) drawing of the lakeside setting of Wordsworth's 'I wandered lonely as a cloud' poem.

At the centre of The Eyre Affair is the contradiction-entailing root that a person is both actual and fictional. Let $P$ be ' $x$ is both actual and fictional': $P$ is true of several characters in The Eyre Affair, yet it entails a contradiction $(Q)$, namely that $x$ is actual and it is false that $x$ is actual. To say that $x$ is fictional just is to say that $x$ is not actual (or it is false that $x$ is actual); so no person can be both actual and fictional. This is a fact of everyday linguistic usage. One qualification is required, however, to head off an 
objection. The Eyre Affair is set in England, suitably redescribed, and some theories of fictional discourse (including Meinongian theories) treat historical characters, events, and places in fiction as fictional objects. On such a theory, $x$ can be both fictional and actual, since the proposition 'England is both actual and fictional' is true. Here is not the place to examine this theory, so I shall simply revise the contradiction-entailing $P$ to read ' $x$ is both actual and (purely) fictional'; this excludes historical characters, events, and places in fiction. No person can be both actual and (purely) fictional, for to say that $x$ is (purely) fictional just is to say that $x$ is not actual. All occurrences in this paper of 'is fictional', where not explicitly adjusted, should therefore be read as elliptical for 'is purely fictional'.

Applying Lewis's method of union to The Eyre Affair, the novel is split into consistent fragments, such that in no fragment is it true both that Jane Eyre is actual and that Jane Eyre is (purely) fictional. It is true in The Eyre Affair that she is actual and true in The Eyre Affair that she is fictional, but it is not true in The Eyre Affair both that she is actual and that she is fictional. Moreover, according to Lewis's account, it is true in The Eyre Affair that Jane (and every other PDR) is not both actual and fictional. There is no way, then, of retrieving Fforde's story from the fragments. Using Lewis's revised method for dealing with impossible fictions, the raison d' être of this fiction disappears. If an acceptable theory of fiction must not depart excessively from intuitive accounts of what is true in the fiction, Lewis's theory is not acceptable.

\subsection{Fixing impossible fictions}

What might the possible worlds semanticist say in response? One option is to deny that 'Jane is both actual and (purely) fictional' entails a contradiction. It might seem that, to make The Eyre Affair consistent, all we need is a theory of transworld identity of objects such that $a$ in the 'real' world can be identical with $b$ in the 'written' world. This would make it metaphysically, and hence logically, possible that $x$ can be both actual and fictional. However, this move - even if available ${ }^{9}$ - would not suffice. The theorist attempting to render The Eyre Affair consistent would have to show that such a theory is true in the fiction. There is no reason to think that Routley's Thesis applies only to the logic of inference: just as an author can stipulate almost any logic, an author can stipulate almost any metaphysics. In fact, Fforde's novel - as captured in the front cover image ${ }^{10}$ - suggests that the transition between the 'real' and the 'written' is not merely a matter of swapping worlds. The flesh-and-blood person (and heroine of The Eyre Affair) Thursday Next who 'enters' the novel Jane Eyre becomes an entity of a very different sort, namely words on a page; the fictional character Jane Eyre undergoes the reverse transition. But language is abstract and flesh is not; this logical absurdity is the point of the fiction. ${ }^{11}$

A different option for the possible worlds semanticist is to say that the contradictionentailing root in The Eyre Affair is merely peripheral to the story, and can be quarantined without too much damage. This is also unconvincing, however; even the book's back cover blurb reads that 'Jane Eyre is plucked from the pages of Brontë's novel' and the (actual)

Australasian Journal of Logic (15:2) 2018 Article no. 2.4 
detective Thursday Next must 'enter a novel herself to avert a heinous act of literary homicide'. ${ }^{12}$

Probably the best move for the possible worlds semanticist is to say that, although ' $x$ is both actual and (purely) fictional' entails a contradiction, and although this theme is central to the novel, The Eyre Affair is consistent - just because it is a fiction-within-afiction. Jane is actual only in the embedded fiction (which is a suitably rewritten version of Jane Eyre), and fictional only in the outer fiction - and each fiction represents a distinct consistent world. This move would also fail, however, since the contradiction-entailing root simply reemerges. In the outer fiction, Jane Eyre is both actual and fictional. She is actual, because she interacts causally with actual people and actual inanimate objects. But she is also fictional because (in the outer fiction), while she is imprisoned by the kidnappers, all copies of Jane Eyre rewrite themselves; readers notice 'strange goings-on around the area of page one hundred and seven', one commenting 'Eyre was written in the first person; as soon as the protagonist has gone it's anyone's guess as to what happens next'. So, reading The Eyre Affair as a fiction-within-a-fiction does not suffice to eliminate inconsistency.

The starting-point of a semantics of The Eyre Affair must be that rendering the fiction consistent will eliminate the central joke. So, to summarize, Lewis's revised analysis of truth in impossible fictions fails because it produces the intuitively wrong set of truths in fiction - and there is no fix in sight. ${ }^{13}$ Of course, Lewis did not guarantee that his method of union would work for all impossible fictions; he said that 'the very hardest cases' are 'meant to defy our efforts to figure out what's true in the story' (1983, p. 277). But this is surely not true of The Eyre Affair; we do figure out what happens in the story.

Alternatively, the possible worlder might say, as did Parsons, that although his or her own theory does not accommodate every case of fiction, it 'seems to work well in the cases we're comfortable with' - and 'perhaps that's all we should expect' (Parsons 1975, p. 83).

\subsection{Do impossible fictions matter?}

But can we be happy with this response? It might be tempting to dismiss fictions like The Eyre Affair, since this novel is a metafiction - a fiction that (directly or indirectly) emphasizes its own fictitiousness. However, metafiction has a long history. Such fictions can be traced back at least as far as the ancient Greek dramatists, for example Aristophanes' The Frogs. In this fiction, Euripides and Aeschylus compete to be judged the greater tragedian. The match is to be decided by weighing their verses in a scale 'like a pound of cheese' - a line including the word 'chariot' naturally weighing more than one including the word 'mace'. ${ }^{14}$ Theorists of fiction are prone to dismiss works like The Frogs and The Eyre Affair, in favour of what Charles Crittenden called 'standard fiction' - that is, 'novels and stories taking familiar sorts of situations as settings and concerning normal human beings' (Crittenden 1982, p. 332). But this strategy has little chance of success. For one thing, what is 'standard' varies across different cultures and time periods; e.g., magic realism - which can include logical impossibilities - is arguably 'standard' in Latin American literature. 
Moreover, although Crittenden and others assume that ' $[\mathrm{m}]$ ost of what is thought of as great literature' falls into the 'standard' category' (ibid., p. 332), metafictions are amongst some of the most revered works. More than a third of the authors on renowned literary critic Harold Bloom's (1994) core list of canonical Western writers wrote metafictions.

In any case, the difficulty for the possible worlder is that The Eyre Affair is an impossible fiction. Can this category legitimately be ignored by a semantics of fictional discourse? The cost of such a strategy would be high (see Proudfoot 2006). To take just one example, many nineteenth-century European and American novels count as impossible fictions by Lewis's definition; these are fictions that both describe a character's thoughts and also imply that these thoughts are undisclosed. Entire novels have been premised on the fact that the central character's inner life is not disclosed. The Scarlet Letter is a good example of this; and many of the great nineteenth-century novels have similar themes - for example, Anna Karenina, Madame Bovary, Middlemarch, and The Portrait of a Lady. (Presumably these would all be 'standard' fictions for Crittenden.) Clearly, there is no possible world in which the omniscient narrator speaks truly when disclosing that which he or she claims is undisclosed. The consequence of ignoring impossible fiction - that a semantics would have to discount these canonical fictions - is unthinkable.

\section{Terence Parsons, Edward Zalta, and 'merely' impossible objects}

In this section I apply the CEP to the theories of impossible fiction offered by the most influential of Routley's Meinongian contemporaries - Parsons and Zalta. With regard to impossible fictions, Parsons agreed that 'it is sometimes difficult to excise the inconsistency without doing violence to the plot' (1979b, p. 657). His solution was to distinguish between an 'impossible' and a 'contradictory' object; impossible fictions depict only the former, and this does not lead to contradiction or explosion. Zalta used a different logical apparatus but in essence made the same move.

Parsons made a much-discussed distinction between 'nuclear' and 'extranuclear' properties or predicates. A property is nuclear if it is commonly regarded by philosophers as an 'ordinary' property (1979a, p. 102); ${ }^{15}$ it is extranuclear if it is ontological, modal, intentional, or 'technical' (e.g. being complete) $\left(1980\right.$, p. 23). ${ }^{16}$ The theory then drives a wedge between the complement of a property and its negation for nuclear properties: a nuclear property $p$ is the negation of a nuclear property $q$ if and only if, for all real objects, if an object has $q$ then it lacks $p$ (ibid., p. 19). As illustration, consider the fiction in which a mathematician squares a circle. Using Parsons' notion of nuclear property negation, although no real object can possess both squareness and non-squareness (this would be a 'contradictory' object), some nonexistent object can and does possess both squareness and non-squareness (this is a merely 'impossible' object). According to Parsons, the former is an object the positing of which 'infringe[s] the law of contradiction'; the latter is merely 
an object that 'has properties which no real object could have' (ibid., p. 42). In short, $(S x \& \sim S x)$ is not a contradiction and so can be true without triggering an explosion.

The analogous distinction in Zalta's theory is between 'exemplifying' and 'encoding'; according to Zalta, these are distinct modes of predication, the former the ordinary way of possessing a property and the latter the way in which representations 'involve' properties (1988, p. 18). Zalta distinguished the complement of a property from its negation in the case of encoding: for any object $o$ and property $p$, if $o$ fails to exemplify $p$, then it exemplifies not- $p$ (and vice versa), but this is not so for encoding. The formal development of the theory then ensures that, although no object can exemplify both squareness and non-squareness, an object can and does encode both squareness and non-squareness (ibid., p. 113). ${ }^{17}$ Using Parsons' terminology, I shall call the former a 'contradictory' object and the latter an 'impossible' object. As for Parsons, positing the latter does not lead to contradiction or explosion.

Parsons' and Zalta's theories may appear to have the resources for dealing with The Eyre Affair. Considering Zalta first, in his account fictional characters are nonexistent abstract objects that encode the properties attributed to them in the fiction and exemplify other properties, such as nonexistence (Zalta 1986, p. 451). Applying this to The Eyre Affair, Jane Eyre encodes both the property of being actual and the property of being non-actual, and so is a merely 'impossible' object.

For Parsons, things are not so simple. Since his solution to impossible fictions applies only to nuclear properties, it does not address the contradiction-entailing root in The Eyre Affair, namely that Jane Eyre is both actual and fictional. Moreover, in his theory, fictional characters are nonexistent concrete objects that possess the nuclear (but not the extranuclear) properties attributed to them in the fiction, in addition to the extranuclear properties that in reality they possess. ${ }^{18}$ (If fictional objects were to possess the extranuclear properties attributed to them in the fiction, the theory would be committed to existent nonexistent objects - a counterexample to Parsons' account of fictional objects analogous to Russell's 'existent round square' counterexample to Meinong's theory (Russell 1905, p. 533).) The result is easily generated counterexamples. For example, on Parsons' theory it is not true that Jane Eyre is actual, and so not true that she is both actual and fictional Jane Eyre is not even a 'merely' impossible object.

There is a potential fix in Meinong's notion of 'watered-down' ('depotenzierte') states of affairs (Meinong 1915/1972, p. 291). ${ }^{19}$ This strategy was to offer Meinong's theory protection against Russell's 'existent round square' counterexample: for Meinong, the proposition 'The existent round square does not exist' is innocuous, stating consistently and truly that the round square possessing depotenzierte existence lacks full-strength existence. ${ }^{20}$ Following Meinong, Parsons introduced 'watered-down' nuclear versions of extranuclear properties: ${ }^{21}$ on his theory, a real object has the nuclear version of each of its extranuclear properties - even an object that is real only in fiction has nuclear versions of the extranuclear properties attributed to it in the fiction (1980, p. 198). There is scope, then, for Parsons to say that the fictional object Jane Eyre is both actual and fictional, where 'is ac- 
tual' and 'is fictional' signify only depotenzierte versions of the corresponding extranuclear properties attributed to her in the fiction.

It should be obvious, however, that in general this 'watering-down' strategy will not prevent counterexamples: for example, intuitively, what is true in the fiction is that Thursday Next really exists, rather than existing only in some depotenzierte sense. In addition, the watering-down strategy merely reinforces the impression that the distinction between 'impossible' and 'contradictory' objects is bogus. For a counterexample to Parsons' theory, consider this fiction: 'Bill created an impossible object $a$ - that is, an object having a combination of properties that no real object could have. But Bill was trumped by Ben, who created a contradictory object $b$ - that is, an object having a combination of properties that no object could have. Bill sulked.' $a$ and $b$ are distinguished in the fiction but not in Parsons' theory.

Zalta claimed that his theory had the advantage over Parsons' account that it 'doesn't leave us with the difficulty of trying to say what the "watered-down versions" of extranuclear properties are' (McMichael and Zalta 1980, p. 312). However, analogous counterexamples can be targeted against Zalta's account. For example, this fiction: 'Edward Zalta was introduced to Bill and Ben. Bill produced an object encoding both squareness and non-squareness, but Ben produced an object exemplifying both squareness and nonsquareness. Zalta was amazed at this turn of events.' According to the fiction, two objects were produced; yet on Zalta's theory the sentence 'Ben's object is square and non-square' can be true only if 'is' means encodes - in which case, Bill and Ben do not produce distinct objects. $^{22}$

Proponents of Parsons' or Zalta's theories might reply that my 'Bill \& Ben' fictions merely purport to describe genuinely contradictory objects, and that in these stories Bill sulks and Zalta is amazed merely because they mistakenly believe that a contradictory object has been created. But this reading is implausible; certainly we could invent fictions in which these characters are deluded, but these would have to differ from the fictions just described (for example, by my including in the Zalta story a new penultimate sentence 'Ben smiled as he pocketed the bottle of hallucinogenics with which he had drugged Bill and Zalta'). Moreover, this sort of explaining away of inconsistent fictions could not work generally: it would be plainly wrong to say, for example, that in The Eyre Affair Thursday Next merely mistakenly believes that real people enter poems. ${ }^{23}$

So, to summarize, both Parsons' and Zalta's Meinongian semantics of fictional discourse have the same downside as Lewis's analysis: there are truths in fictions - including impossible fictions - that are not captured by the theory.

\section{$5 \quad$ Routley on usual and esoteric fictions}

When Routley said that fictions 'have regularly revealed serious weaknesses in each new theory proposed', he added the parenthesis '(at least until recently?)', hinting that his own 
theory of objects might prove satisfactory (1980, p. 537).

In Routley's view, 'Although there is no uniform logic of fiction, there will be an emerging set of logical principles for usual works of fiction' - works that 'do not tax their readers with non-standard logical, or arithmetic, backdrops' (1979, pp. 11, 10). 'Usually', he said, 'the background logic is, by default, that of ordinary discourse, and the closure conditions are ... those of relevant logics, e.g. closure under provable entailments, under adjunction' (ibid., p. 10). And so the logic to employ in determining what is true in usual fiction, Routley claimed, is a (multiply intensional) relevant logic: 'fictional worlds resemble the incomplete worlds of relevant logics' (ibid., p. 8). A relevant logic can omit logically necessary truths that are extraneous to a fiction, allow incompleteness, and also allow inconsistency without trivialization - all problems for Lewis's account (see Proudfoot 2006). Of course, given Routley's Thesis, even this logic runs into problems 'if upgraded to the logic of fiction, or acclaimed as [a] comprehensive theory of fiction'; in principle fictions can be created that 'violate each of the closure conditions of relevant logics', he said (ibid., pp. 14, 15).

Routley's theory incorporated a contextual semantical theory and noneism. The claim [1] 'Sherlock Holmes lived in 221B Baker Street' is 'true in one context, say, $c$, and not true in another, say, s. ... [T] here is no inconsistency because $c$ differs from $s$ ' (ibid., p. 17). There is no need, then, for an 'in the fiction' operator, or for a distinction in classes of properties or modes of predication, in order to block the sentence 'Sherlock Holmes exists' from expressing a true claim. Claims such as [1] are to be construed as involving 'a shift of the base situation with respect to which truth assessment is made, from the usual [actual world] $T$ to a new situation $a_{1}$ determined by c' (ibid., p. 17). In the case of 'usual' fiction, the base shifting function selects the set of 'normal worlds (including the actual world)'; and in the case of 'esoteric' fiction this is the set of 'all' worlds (ibid., p. 27).

Routley's theory of fiction, as he himself acknowledged, 'leaves several important areas open' (1979, p. 28). For example, he said that, in addition to truths explicitly stated in a fiction (or entailed by those explicit truths), there are also 'material additions' consisting of 'factual or quasi-factual material'; these are not 'explicitly spelt out' in the fiction (1980, p. 542). But he did not tell us how to determine these additions for any given fiction; instead he said that there is 'some elasticity' in what is true in a given fiction, and a 'loose, open-ended and awkwardly intensional' account might be the best we could hope for (1979, p. 6; 1980, p. 542). Similarly, although Routley said that what determines transworld identity of fictional objects is 'qualified author sayso, the qualification being that a core of features of the object must be preserved' (1979, p. 24), he did not fill out this qualification; instead he said that there is 'no need to try to settle every case of identity or difference here, or accordingly to try to explain what is meant by a core ... identity criteria for objects are sometimes a don't care' (ibid., p. 25).

On one point, Routley was quite definite. He said: 'the worlds of a semantical analysis adequate to model the structure of fictional discourse will have to include worlds that are inconsistent, logically and also physically' (1980, p. 546). By adding inconsistent worlds, it seems, there is hope of capturing our intuitions about deliberately inconsistent fictions.

Australasian Journal of Logic (15:2) 2018 Article no. 2.4 
Routley's $21^{\text {st }}$ century inheritors make the same claim. In Graham Priest's canonical paper 'Sylvan's Box: a Short Story and Ten Morals', an object both exists and does not exist; the box containing the object is 'absolutely empty, but also had something in it' (1997, p. 575). This too is a contradiction-entailing root. This story is inconsistent yet 'coherent', Priest claims, and so the logic of the story 'must be paraconsistent' (ibid., pp. 580, 579). The story also shows, he says, that 'There are, in some undeniable sense, logically impossible situations or worlds.' (ibid., p. 580). In sum, 'we need inconsistent worlds to handle inconsistent fictional objects' (Priest 2016a, p. 123).

Priest posits 'possible, impossible, and open worlds' (2016a, p. 139). Impossible worlds are 'worlds where the laws of logic may be different' (ibid., p. 16). Possible and impossible worlds are logically closed. The story 'Sylvan's Box' describes a 'logically impossible' world, Priest says, where a logically impossible world is 'closed under an appropriate inference relation' (1997, p. 580):

Representations, as I have noted, are closed under a logic. The logic in the case of Sylvan's Box is paraconsistent; that is, a logic in which contradictions do not imply everything. Certain inconsistencies hold in the story, but not everything does. I would like to take this as an argument to the effect that a paraconsistent logic is the (uniquely) correct logic. (Priest 2016a, p. 122)

Given this characterization of 'Sylvan's Box', in the following sections I first assume that, according to (what I shall call) the Routley-Priest semantics for impossible fictions, impossible fictions depict impossible worlds as these are understood in Priest (2016a). (I turn to 'open' worlds, which are not logically closed, in Section 9.)

\section{Impossible fictions and depotenzierte contradictions}

Priest's claim that 'Sylvan's Box' shows that there are 'in some sense' logically impossible situations or worlds appears to qualify his general commitment to impossible worlds: these situations or worlds may be impossible merely in some sense. Likewise Routley's remark that an analysis of fiction must include "worlds that are inconsistent, logically and also physically ...' appears to qualify the same commitment, since it continues 'or else somehow simulate such worlds': inconsistent states of affairs may merely be somehow simulated. In each case the rider is significant, since it brings to mind Parsons' distinction between contradictory and 'merely' impossible objects - and hence raises the question whether

Routley's and Priest's 'logically impossible possible world[s]' are also 'merely' impossible. ${ }^{24}$

Meinongians in general are vulnerable to exactly this objection. As we have seen, Parsons distinguished what he called 'fullblooded' negation (according to which the negation of $p$ is the complement of $p$ ) from 'nuclear' negation (according to which the negation of $p$ is $q$ if and only if, for all real objects, if an object has $q$ then it lacks $p$ ). This is the watering-down strategy, used to provide 'merely' impossible objects - and thereby a 
semantics for impossible fictions. The Routley-Priest theory in effect extends Parsons' strategy to sentence negation; and so it raises the question whether this theory provides merely depotenzierte negation and conjunction - and in consequence, merely depotenzierte contradictions.

Max Cresswell pressed this point when he said, 'The fact that we can reinterpret \& and $\sim$ so that $\langle \&, a,\langle\sim, a\rangle>$ is true in a possible world no more shews us how a contradiction could ever be true than calling birds "pigs" shews us how pigs could fly' (1973, p. 41). Likewise, according to Jack Copeland, the only sense that the Routley-Priest theory gives to 'inconsistent' is 'a purely technical sense'; in this semantics, he claimed, 'formulae of the form $A \& \sim A$ turn out to be just counterfeit contradictions ... People who insist that there can be no true contradictions will agree that $A \& \sim A$ can be true' (1986, p. 489; see also Copeland 1979). Timothy Smiley also wrote:

[T] he fact that a logical system tolerates $A$ and $\sim A$ is only significant if there is reason to think that the tilde means 'not'. Don't we say 'In Australia, the winter is in the summer', 'In Australia, people who stand upright have their heads pointing downwards', 'In Australia, mammals lay eggs', 'In Australia, swans are black'? If 'In Australia' can thus behave like 'not', perhaps the tilde means 'In Australia'? (1993, p. 17)

This objection, and the replies to it by modal Meinongians and others, raise considerably larger issues than a debate over the best semantics for impossible fictions. Consider just one big-picture reply, made by proponents of the Routley-Priest approach to critics of Meinongianism more generally. Priest claims that there is 'absolutely no reason' why 'everything said by one side must be translated into terms intelligible to the other'; the critic 'may just have to learn a new language game' (2011, p. 251). ${ }^{25}$ Applied to the criticism that purported true contradictions are 'just counterfeit', this is the reply: only if you ignore the new paradigm. This reply depicts the critics as logical Luddites. ${ }^{26}$ The dispute with Cresswell et al. shifts to that of the criteria to be employed for overlapping paradigms and whether Routley's and Priest's use of the logical connectives satisfies such criteria.

However, even if Routley's and Priest's critics are Luddites, their claims about contradiction are the basis of a prima facie counterexample to the Routley-Priest semantics of impossible fictions. If the fiction-writer can write a fiction according to which there are true contradictions in the Cresswell-Copeland-Smiley sense of 'contradiction', the semantics would not distinguish this from a fiction according to which there are true contradictions in the Routley-Priest sense of 'contradiction' - just because there is no possible or impossible world at which a contradiction in the classical sense is true. And Routley's Thesis itself guarantees that the former fiction is in principle possible - the logic of a fiction 'may be any logic that the author chooses to impose', he said.

Routley's Thesis, of course, predicts counterexamples to any semantics of fiction. The question, then, is: how many impossible fictions are counterexamples to the Routley-Priest theory - and how many of these are extant rather than invented? In Sections 7-9, I argue as 
follows (refashioning Routley's terminology of 'usual' and 'esoteric'): even if the RoutleyPriest theory works for some esoteric impossible fictions, it fails to capture the usual sort of extant impossible fictions.

\section{Inconsistent vs paradoxical fiction}

In Priest's LP, a contradiction $(A \& \sim A$ ) that is true is also false; in the terminology of LP, it is 'paradoxical' (Priest 1979). We can in principle distinguish a fiction according to which $(A \& \sim A)$ is true-and-true-only from a fiction according to which $(A \& \sim A)$ is paradoxical. For brevity, I shall call the former an inconsistent fiction and the latter a paradoxical fiction. However, the Routley-Priest theory of impossible fiction seems unable to distinguish these fictions, just as Parsons' semantics could not distinguish between 'contradictory' and 'impossible' fictional objects. This is because, on the Routley-Priest theory, there is no impossible world in which a contradiction is true-only - just as, for Parsons, there is no object possessing contradictory properties.

\subsection{Sylvan's Bottle}

There is no obstacle in principle to writing a story around a contradiction that is true-only. In such a fiction, although it would be true that $A$ is both true and false, it would not be true that $(A \& \sim A)$ is both true and false. Here, then, is an example:

\section{Sylvan's Bottle}

Since that amazing day twenty years ago, when Graham Priest discovered the now-famous Sylvan's Box, additional impossible objects have been found; and paraconsistent logic dominates most philosophy departments (though in New Zealand a few resist). Graham was almost accustomed to the experience of the Box, even slightly jaded. But one day in 2017, in the jungle on Plumwood Mountain, while he was watching the construction of a highway of stone steps leading to a new Buddhist monastery, his nonchalance toward impossible objects was to vanish.

The excavator driver clearing the way braked suddenly and pointed to a bundle of sacking sticking out of the earth. The sacking looked as though it was used originally to wrap tree seedlings. Graham cautiously undid it, to find a full bottle of a Yarrunga Field shiraz, sadly too old for drinking. Why would anyone bury this? Then he noticed that the bottle, which a second ago had surely been full, was empty. No, he corrected himself, with a feeling of déjà vu, it $i s$ full - and also empty.

He watched the driver stare at the bottle with the shock and bewilderment that he too had experienced decades earlier. Here we go again, he sighed, anticipating inconsistent events, as had befallen him and Nick Griffin in 1997, and 
had followed every discovery since of an impossible object. But nothing happened. Apart from the sheer fact of the bottle and its inconsistency, everything seemed perfectly normal. Was there something different about this impossible object, Graham wondered.

He checked that the bottle was still both full and empty. This time he noticed that a note was caught in the layers of sacking. The note consisted of three bullet points: 'Unexpected - this contradiction is true only', 'Kleene's matrices inapplicable', and 'Must hide this from Priest'. The note was in Richard Sylvan's distinctive handwriting. Priest whistled. Richard had buried this bottle!

Richard must have wanted to save Graham from this blow. There were things on Plumwood Mountain that were not dreamt of in the system LP.

'Sylvan's Bottle' is more than merely schematic and there is no obvious reason why it could not be further developed. It describes a world in which some contradiction - the root 'This bottle is both full and empty' (along with the entailed proposition 'This bottle is both full and not-full') - is true-only. However, according to the Routley-Priest analysis and using the system LP, at the impossible worlds in which 'This bottle is both full and not-full' is true, it is also false. Here we have a discrepancy between the intuitive truths in this fiction and the truths delivered by the theory.

How might the proponent of the Routley-Priest theory of impossible fictions reply? It would do no good to say that, since neither classical nor paraconsistent logic will allow a true-only contradiction, such cannot be the case in the fiction. Routley's Thesis has pointed out the flaw in this claim. The fact (if it is a fact) that 'outside' the fiction, if $A$ is paradoxical then $(A \& \sim A)$ is also paradoxical, does not make this true in any particular fiction. ${ }^{27}$ Priest himself says, moreover, that 'one can, in fact, conceive anything, whether or not it is impossible' (2016b, p. 2649). The answer to the question 'But how can we make sense of a true-only contradiction?' is: that's just how the fiction-writer conceived the world of the story.

Proponents of the Routley-Priest theory might object that I cannot simply read off from 'Sylvan's Bottle' that in some world a contradiction is true-only; however, the very same objection could be made against their own strategy of reading impossible worlds (at which contradictions are true and false) off impossible fictions. Likewise, they could hardly object that in my fiction the characters Graham and Richard merely mistakenly believe that some contradiction is true-only, since this this would be analogous to a criticism of their own theory - namely, that Priest's story 'Sylvan's Box' is in fact consistent, and the characters who think otherwise are deluded (e.g. Hanley 2004, Nolan 2007; see note 2). Against this objection, Priest says of his fiction that 'anyone who misapplied the principle of charity to interpret the story in a consistent way would have entirely misunderstood it' (1997, p. 580 ), and I would make the same reply here.

In sum, 'Sylvan's Bottle' is a prima facie inconsistent, rather than paradoxical, fiction. Hence it is a counterexample to the Routley-Priest theory of impossible fictions (insofar as 
the theory claims that such fictions depict logically closed impossible worlds).

\subsection{Are extant impossible fictions inconsistent or paradoxical?}

If the Routley-Priest theory is to defend the claim that positing impossible worlds offers a 'natural' treatment of impossible fictions, it must claim that contradictions in (most) extant impossible fictions are paradoxical rather than true-only. To test the plausibility of this claim, I shall take The Eyre Affair as a test case.

Is this novel an inconsistent or a paradoxical fiction? As above, let $P$ be ' $x$ is both actual and (purely) fictional'. Let $Q$ be $P$ 's entailment, ' $x$ is actual and it is false that $x$ is actual'. In order to decide whether, according to The Eyre Affair, $Q$ is true-only or paradoxical, we must begin with our intuitions about the fiction. In The Eyre Affair Fforde clearly attempts to make it plausible that $Q$ is true: He writes, for example: 'The barriers between reality and fiction are softer than we think; a bit like a frozen lake. Hundreds of people can walk across it, but then one evening a thin spot develops and someone falls through; the hole is frozen over by the following morning.'. And again: 'almost everything one can think of can be bent and stretched ... [including] space, time, distance, and reality'. Part of the literary merit of the fiction is exactly how Fforde manages this fine balance. Notably, his making the central inconsistency plausible - that is, persuading us that it is true that someone is both actual and (purely) fictional - is not parallelled by any attempt to show this proposition to be false. After all, were this proposition false, the central joke would vanish. The Eyre Affair, it seems, encourages us to say that $Q$ is true-only.

What might The Eyre Affair be like if it were a paradoxical fiction - if, for example, Fforde had devoted as much space to suggesting that $Q$ is false? One way to construct a paradoxical fiction - and a likely way if the fiction is to be coherent - would be for the novel to consist of conflicting narratives, so that a contradiction is true in one narrative and false in another. Multiple narration (by different narrators) is a common device of literary and other fictions - for example, novels such as William Faulkner's The Wild Palms or films such as Rashomon. Such works cannot simply be explained away as involving different fictions (as in the case of a collection of short stories), since the fact of different narratives is essential to the work; nor as fictions embedded within an implicit consistent narrative, as there is no reason (other than to make the work consistent) to assume such a narrative. Rather, the device of multiple narration is frequently used to render it unclear just what is true in the fiction. In some fictions, there are conflicting narratives but no variation of narrator; parts of the story are simply repeated with changes to the plot - as, for example, in John Fowles' novel The French Lieutenant's Woman. This provides a model for a paradoxical fiction; in such a fiction the change to the plot consists in modifying (from true to false) the truth-value of a contradiction. The Eyre Affair is nothing like this, however, and so again appears to be inconsistent rather than paradoxical. ${ }^{28}$

If this account of The Eyre Affair is correct, it is not adequately represented by an impossible world at which all contradictions are false as well as true. Hence we have 
a prima facie objection to the Routley-Priest theory, namely that it fails to distinguish inconsistent from paradoxical fiction. Moreover, the properties of The Eyre Affair that make it an inconsistent rather than paradoxical fiction are shared by many other extant fictions, whereas few extant fictions fit the model just proposed of a paradoxical fiction. This suggests that contradictions in (most) extant impossible fictions are true-only - the opposite result to the one that the Routley-Priest theory needs.

\section{Impossible fictions and open worlds}

According to Priest, 'arbitrary intentional states ... are not closed under entailment' and so, to represent such states, 'we are led to posit a class of unclosed, or open, worlds'; at these worlds 'all formulas may behave arbitrarily' (2016a, p. 22). Perhaps, then, an impossible fiction in which a contradiction is true - only depicts an open world in which a contradiction's being true does not entail that it is also false - despite LP's being in reality the '(uniquely) correct' logic. Priest remarks:

It seems to me that, though the correct (paraconsistent) logic is the default logic for reasoning about a fictional situation, one can, in some way, moderate this in such a way as to accommodate the demands of the particular story. ... (2016a, p. 122)

As to Routley's view, he told us relatively little about 'logically esoteric' works of fiction (1979, p. 27). However, he said that 'there are in principle no restrictions as to type' of worlds of fiction, and that the logic of fictional worlds is 'much more anarchical than that of relevant worlds' (ibid., pp. 7,10 ). This seems at least consistent with the idea of open worlds.

So the modal Meinongian might respond to my counterexamples in Sections 7.1 and 7.2 as follows: inconsistent fictions represent open worlds whereas paradoxical fictions represent logically impossible worlds. Not only, the Meinongian might say, does the category of open worlds defeat my examples of invented and extant inconsistent fictions, but the distinction between inconsistent and paradoxical fiction is in fact an argument for open worlds. ${ }^{29}$

However, it is by no means clear that this response would improve the situation for the Routley-Priest semantics. The most that could then be said, it seems, about 'Sylvan's Bottle' or The Eyre Affair is: each fiction depicts an open world at which what is true in the fiction (both logically and as a matter of fact) is also true. This, though, would not be to provide a semantics but merely a list of truths in the open world corresponding to the fiction. The open world 'semantics' is, so to speak, nothing more than a mirror or echo of the fiction: it consists of nothing more than a listing of the sentences that are true in the fiction. A semantics is distinguished from a mere list of truths in that it must (at least): explain problematic features of the fiction (e.g., how both $A$ and $\sim A$ can be true); supply an account of the inferential behaviour of sentences in the fiction; and provide an account 
of the meanings of key terms of the fictional discourse, especially those whose meaning within the fiction differs (or prima facie seems to differ) from the meaning these terms have in ordinary non-fictional discourse (e.g. the term 'possible'). Can the modal Meinongian provide this? The prima facie question for an 'open world' semantics is: if an open world really is a world where formulae behave arbitrarily, can the semantics be any more than a list of formulae - an uncritical and unanalyzed echo, in effect, of the fiction?

According to Priest, principles can be added to an open world in order to legitimize inferences made using intentional operators, so that not all formulae would be behaving arbitrarily. For example, we may presume that principles could be added to the open world represented by 'Sylvan's Bottle', in order to allow true-only contradictions. However, this is merely to add further formulae to the list - more detail to the mirror. Routley's notion of a 'source book' can be used to make the same point. According to Routley, 'For each [fictional] object, there is a source book which tells its "story" what it is like, what it does, and so forth' (1980, p. 353). The most we can say about open worlds, it seems, is that at the world represented by The Eyre Affair everything true in the source book for this fiction is true. But what further contribution does positing an open world make to our understanding of the logical properties of the fiction?

Moreover, Priest immediately continues the remark (quoted above) ending 'one can, in some way, moderate this in such a way as to accommodate the demands of the particular story.' with: 'How one does this, though, is another matter' (2016a, p. 122). What are the logical principles that govern the worlds to be used in the semantics of inconsistent (rather than paradoxical) fiction? And, in particular, what are the closure properties? ${ }^{30}$ The modal Meinongian must answer these questions if the counterexamples in Sections 7.1 and 7.2 are to be defeated.

Previously I argued that possible worlds semantics works well enough for a range of, but importantly not all, consistent fictions (Proudfoot 2006). We might say (setting aside the Cresswell-Copeland-Smiley objection) that impossible worlds semantics gives us a semantics for a subset of inconsistent fictions, the 'paradoxical' kind. But most extant inconsistent fictions remain unexplained. The pressure then is on the modal Meinongian to construct an open worlds semantics of fiction and test it against these counterexamples. Of course, though, Routley's Thesis tells us that, whatever open worlds semantics is constructed, it will be possible to counterexample it.

\section{IFP vs IFI fiction}

The distinction between inconsistent and paradoxical fiction is not the only distinction to be made amongst impossible fictions, nor the only one to create a challenge for the modal Meinongians' claim to provide a semantics for such fictions. Amongst impossible fictions, I shall argue, we can distinguish those that are depicted as possible from those that are depicted as impossible.

Australasian Journal of Logic (15:2) 2018 Article no. 2.4 
In fiction what is (in fact) impossible may become possible - just as what is (in fact) false may become true. As above, let $P$ be a contradiction-entailing root. It follows that $\diamond P$ (as well as $P$ itself) is false at every possible world, including the actual world. In a fiction, however, it can be true, not only that events impossible in the actual world really happen, but that they are possible. In a fiction, it can be true that $\diamond P$. An impossible fiction that is depicted as possible, I shall say, is a fiction such that $(P \& \diamond P)$ is true in the fiction, where $\sim P$ is true in the actual world.

In contrast, an impossible fiction that is depicted as impossible is a fiction such that $(P \& \sim \diamond P)$ is true in the fiction, where $\sim \diamond P$ is true in the actual world. In this fiction, events happen that are impossible in the actual world and are acknowledged in the fiction to be impossible. For short I will refer to an impossible fiction in which in fact impossible events are depicted as possible as an IFP fiction, and an impossible fiction in which in fact impossible events are depicted as impossible as an IFI fiction. ${ }^{31}$

What are examples of IFP fictions? We need look only at additional examples of fictions in which actual people and fictional characters interact - for example, films such as The Purple Rose of Cairo and Last Action Hero. In these fictions, a character from an embedded film leaves that film by 'walking out of' the screen against which the film is being projected, or a member of the audience watching an embedded film 'walks into' that film by walking towards the screen. It is crucial to the comedy that the character who walks out of the screen to exist in the actual world remains fictional and that the actual person who walks into the film (and thereby the fiction) remains actual.

The comedy is based on the fact that, while such states of affairs are in reality impossible, in the fiction these are possible. In both The Purple Rose of Cairo and Last Action Hero it is true, not only that someone is both actual and fictional, but also that it is possible that someone is both actual and fictional. This is signalled by the fictions' treating the events of the fiction as unremarkable - as inconveniences rather than logical impossibilities. Thus, in Last Action Hero someone matter-of-factly remarks 'I've never met a fictional character before'; and in The Purple Rose of Cairo the heroine, who is actual, says of her lover 'He's fictional, but you can't have everything'. As above, let $P$ be ' $x$ is both actual and (purely) fictional'. Ex hypothesi $P$ entails a contradiction $Q$ (that $x$ is actual and it is false that $x$ is actual); and so $\diamond P$ (as well as $P$ itself) is false at every possible world, including the actual world. In both The Purple Rose of Cairo and Last Action Hero, however, $(P \& \diamond P)$ is true, where $\sim \triangleright P$ is true in the actual world.

What are examples of IFI fictions? One is M.C. Escher's pictorial fictions such as 'Drawing Hands', where flesh-and-blood hands become sketches of hands, and 'Ascending and Descending', where figures continually walking upwards from one spot meet those continually walking downwards from the very same spot. Escher's perspective drawings depict, to use Lionel and Roger Penrose's words, 'impossible objects' and create 'contradictory perceptual interpretations' (Penrose and Penrose 1958, p. 31). ${ }^{32}$ Like Fforde, Escher's aim was in part humour; he talked of his 'jokes on perspective' and said that there is 'no end to the funny and impressive impossibilities' that could be created. ${ }^{33}$ In a lecture on 'the 
impossible' he said: 'Sometimes it seems as though we are all obsessed with a longing for the impossible. The reality around us, the three-dimensional world surrounding us, is too ordinary, too boring, too common'. 34

What makes Escher's drawings IFI fictions is that, on seeing them, visual disorientation is unavoidable. In 'Drawing Hands' the impossibility is emphasized by the visual conflict between the two-dimensional paper and the three-dimensional hands, and in 'Ascending and Descending' by the eye naturally tracking the figures in two opposed ways. According to Escher, 'an impossible situation only really stands out when the impossibility is not immediately obvious. If you want to draw attention to something impossible, you must try to deceive first yourself and then your audience, by presenting your work in such a way that the impossible element is veiled ... [and] does not immediately hit the eye'. ${ }^{35}$ When the impossibility does 'hit the eye', however, there is no hiding from it; Escher's drawings do not allow the viewer to think that what he or she is seeing is possible - even in the world of the fiction. Let $P$ now be ' $x$ is both (purely) flesh and (purely) paper' (or ' $x$ is moving both up and down the staircase'). $\diamond P$ (as well as $P$ itself) is false at every possible world, including the actual world. In these pictorial fictions, $P$ is true, even though $\sim \diamond P$ is true in the actual world. Moreover, it is also true in these fictions that $\sim \diamond P$.

IFI fictions are rarer than one might expect. Consider again The Eyre Affair. The image on the cover of the novel has some similarity with 'Drawing Hands', in that a real three-dimensional car emerges from a two-dimensional drawing, but there is none of the visual disorientation of Escher's work. Fforde's novel differs from Last Action Hero and The Purple Rose of Cairo in that it is plainly set in an alternative world where crazy things happen all the time. The heroine Thursday Next 'agree[s] that something odd is going on; something I can't possibly explain', and another character even describes moving from fiction to reality as a 'paradox'. Nevertheless, it is implicit in the novel that this paradox has a solution, since characters 'can jump spontaneously from the pages of novels' ${ }^{36}$ In the same way, although Thursday's reaction to the temporal paradoxes also depicted in the story is 'I might well go nuts trying to figure it out', she acknowledges that 'it would make complete sense to my father'. The Eyre Affair too, despite its bizarre setting, is an IFP fiction. ${ }^{37}$ Likewise my fiction 'Sylvan's Bottle' shows no sign of being anything other than an IFP fiction.

IFP fictions - what sort of possibility?

In The Purple Rose of Cairo and Last Action Hero, (in reality) impossible events occur - and in the fiction it is possible that these events occur. But what sort of possibility is involved? A first attempt at answering this question generates three options:

(1) $\diamond P$ is true at $w$ iff $P$ is true at some (possible or impossible) world.

This corresponds to Priest's use of $\diamond$. According to Priest, $\diamond A$ is true in $w$ iff for some $w^{\prime}$ (in the class of closed worlds) $A$ is true in $w^{\prime}$ (2016a, p. 11). ${ }^{38}$

Australasian Journal of Logic (15:2) 2018 Article no. 2.4 
(2) $\diamond P$ is true at $w$ iff $P$ is true at some possible world (with an appropriate accessibility relationship to $w)$.

This is the standard possible worlds semantics treatment of $\diamond$.

(3) $\diamond P$ is true at $w$ iff $P$ is true at the actual world @ ( $T$, in Routley's notation).

This is analogous to Crossley's and Humberstone's (1977) treatment of their 'Actually' operator, where $A \diamond P$ is true iff $P$ is true at the actual world.

Selecting (1) fails to distinguish between IFP and IFI fictions; since (for the impossible worlds semanticist) there is an impossible world in which $\mathrm{P}$ is true, every impossible fiction is an IFP fiction. This is plainly the wrong result. Selecting (3) has the converse result; assuming that it is actually impossible for $a$ to be both fictional and non-fictional, every impossible fiction is an IFI fiction. This leaves (2), the standard interpretation in possible worlds semantics.

\subsection{Modal Meinongianism and IFP fiction}

By process of elimination, then, clause (2) remains as the only option for successfully distinguishing between IFI and IFP fictions. Can the modal Meinongian use (2) in order to distinguish between IFI and IFP fictions?

A theory incorporating impossible worlds, and using clause (2), appears to have the scope to provide a semantics for IFI fictions. (By 'impossible world' I mean here simply worlds where $A$ is true, even if $\sim \diamond A$ is actually true.) There are impossible worlds in which $P \& \sim \diamond P$ is true and thus resources for bringing this out as true in the fiction. An impossible worlds semantics can bring it out as true in 'Ascending and Descending' both that ' $a$ is moving both down and up the staircase' and 'It is impossible that $a$ is moving both down and up the staircase'.

However, an impossible worlds semantics using clause (2) cannot capture truths in IFP fictions. This is because, by (2), the IFP fiction demands that $P$ is true in some possible world. But ex hypothesi there are no possible worlds in which $P$ is true. Hence, although introducing impossible worlds can bring it out as true in The Purple Rose of Cairo that Tom Baxter is both actual and fictional, the approach cannot bring it out as true in The Purple Rose of Cairo that it is possible that Tom Baxter is both actual and fictional. Clause (1) can do so, but the price, as explained above, is that the semantics is not able to distinguish between IFI and IFP fictions, and so fails to capture intuitive truths in fiction. Moreover, again we must ask: which is more common - IFP or IFI fictions? The examples given just above suggest that the former is more common than the latter. If this is correct, again the Routley-Priest theory fails to give us an account of the majority of extant impossible fictions.

Is there a possible fourth approach that does not use the recursive clauses (1)-(3)? According to Berto (following Kripke (1965, p. 210)):

Australasian Journal of Logic (15:2) 2018 Article no. 2.4 
at non-normal worlds, formulas of the form $£ A$, with $£$ a modal operator, are not evaluated recursively depending on the truth value of $A$ at other (accessible) worlds, but get assigned their truth value directly. Specifically, all box-formulas are false and all diamond-formulas are true. (Berto 2013a)

This approach might seem to provide modal Meinongians with an alternative strategy: instead of using clause (2), or indeed any recursive clause for evaluating diamond-formulas, truth-values are assigned 'directly' to modal formulae. ${ }^{39}$ However, there are two problems with this approach. The first is simply that, as Berto says, 'anything is possible', making it once more impossible to distinguish IFP from IFI fictions. In that respect, the direct approach is no improvement on (1).

However, there may be more mileage in this approach. What is required, in order for the approach to be able to distinguish between IFP and IFI fictions, is a way of making diamond-formulae true in some worlds but false in others. One way of doing this is to make use of the following, which I shall call the direct assignment schema:

(4) $\diamond P$ is true at $w$ (the world depicted by the fiction $f$ ) iff $\diamond P$ is true in the fiction $f$.

With the direct assignment schema in play, it is straightforward to distinguish between IFP and IFI fictions. Let $P$ be a statement that is true in $f$ and impossible in the actual world. $f$ is an IFP $\Leftrightarrow \diamond P$ is true at $w \Leftrightarrow \diamond P$ is true in $f$; and $f$ is an IFI $\Leftrightarrow \sim \diamond P$ is true at $w$ $\Leftrightarrow \sim \triangleright P$ is true in $f$. On this approach, it is at bottom our intuition about what is possible and impossible in the fiction that determines whether the fiction is an IFI or an IFP, and so the theory has the advantage - not shared by the recursive theories discussed above that its claims are in agreement with standard intuitions about the fiction.

The problem with the direct assignment schema, though, is that this advantage, if it is such, is a Trojan horse for Meinongian semanticists. For Meinongian semanticists are clear that their goal is to provide a semantics of fictional discourse. Yet how is the theory embodying the direct assignment schema to be distinguished from semantical nihilism the view that there is no semantics of fictional discourse and moreover no need for such a thing. We have our intuitions about what is possible and impossible in a fiction such as The Purple Rose of Cairo, and beyond that there is very little more to be said.

In summary, then, (4), whatever its advantages, seems to have no place in a semantics for fictional discourse. But, as we have seen, none of (1)-(3) enables the impossible worlder to acknowledge the distinction between IFP and IFI fictions.

One last question. Is 'Sylvan's Box' an IFP or an IFI fiction? The characters' reactions to the 'absolutely empty' box 'with something in it' - for example, 'I could do nothing but gaze, mouth agape' and 'his look turned from curiosity, to incomprehension, to sheer disbelief, mixed, I thought, with a little panic' - does not guarantee the latter, since Thursday Next makes similar protests in the IFP fiction The Eyre Affair. On the contrary, 'Sylvan's Box' makes sense of the Box using various analogies - phenomenological, historical, and 
scientific. Perceiving the Box is akin to the experience (while in a standing train next to a moving one) of being both stationary and in motion. Categorizing the Box as impossible is akin to how Newton would have reacted to the idea that time is relative. And physically the Box is a macro-world Schrödinger's cat. These various attempts to reduce the absurdity of the Box seem to signal that in the fiction it is possible that a box can be both empty and occupied. If so, Priest's very own story is a type of impossible fiction that an impossible worlds semantics cannot handle.

\section{Conclusion}

The problems described in Sections 6-9 present prima facie problems for the Routley-Priest theory of impossible fictions. As Routley's Thesis cautions, the fiction-writer can imagine just about anything - including a true-only contradiction and a world in which the impossible is possible. These are fictions, however, for which the Routley-Priest theory does not provide a satisfactory semantics. Yet extant impossible fictions - and perhaps even the canonical 'Sylvan's Box' - appear to be mostly of this kind. Routley's Thesis has a substantial sting in its tail for Routley himself and for his $21^{\text {st }}$ century heirs.

\section{Acknowledgements}

Thanks to Jack Copeland and two anonymous referees for the AJL for their valuable comments on an earlier draft of this paper.

\section{References}

Berto, F. (2011) Modal Meinongianism and Fiction: the Best of Three Worlds. Philosophical Studies: An International Journal for Philosophy in the Analytic Tradition 152(3): 313-334.

Berto, F. (2013a) Impossible Worlds. The Stanford Encyclopedia of Philosophy (Winter 2013 Edition), Edward N. Zalta (ed.) http: //plato.stanford.edu/archives/win2013/entries/impossible-worlds/.

Berto, F. (2013b) Existence as a Real Property: The Ontology of Meinongianism. Dordrecht: Springer Netherlands.

Bloom, H. (1994) The Western Canon: The Books and School of the Ages. New York, NY: Riverhead Books.

Bool, F.H, Ernst, B., Kist, J.R., Locher, J.L., and Wierda, F. (eds) (1992) Escher: The Complete Graphic Work, including essays by M.C. Escher. London: Thames \& Hudson.

Bueno, O. and Zalta, E.N. (2017) Object Theory and Modal Meinongianism. Australasian Journal of Philosophy [published online, DOI 10.1080/00048402.2016.1260609]. 
Cappelen, H. (2012) Philosophy without intuitions. Oxford: Oxford University Press.

Copeland, B. J. (1979) On When a Semantics is Not a Semantics: Some Reasons for Disliking the Routley-Meyer Semantics for Relevance Logic. Journal of Philosophical Logic 8(1): 399-413.

Copeland, B. J. (1986) What is a Semantics for Classical Negation? Mind 95(380): 478-490.

Cresswell, M.J. (1973) Logics and Languages. London: Methuen.

Crossley, J.N. and Humberstone, L. (1977) The Logic of 'Actually'. Rep. Math. Log. 8: 11-29.

Crittenden, C. (1982) Fictional Characters and Logical Completeness. Poetics 11: 331-344.

Hanley, R. (2004) As Good As It Gets: Lewis on Truth in Fiction. Australasian Journal of Philosophy 82(1): 112-128.

Kaplan, D. (1973) Bob and Carol and Ted and Alice. In J. Hintikka et al. (eds) Approaches to Natural Language. Dordrecht: D. Reider, pp. 490-517.

Kripke, S. A. (1965) Semantical Analysis of Modal Logic II. Non-normal Modal Propositional Calculi. In J. W. Addison, L. Henkin, and A. Tarski (eds) The Theory of Models: Proceedings of the 1963 International Symposium on the Theory of Models. Studies in Logic and the Foundations of Mathematics. Amsterdam: North-Holland Publ. Co., pp. 206-220.

Kripke, S. A. (1980) Naming and Necessity. Oxford: Basil Blackwell.

Lewis, D. (1976) The Paradoxes of Time Travel. American Philosophical Quarterly 13(2): $145-152$.

Lewis, D. (1983) Truth in Fiction. In D. Lewis, Philosophical Papers, Vol 1. New York: Oxford University Press, pp. 261-280.

Lewis, D. (1990) Noneism or Allism? Mind 99(393): 23-31.

Lewis, D. (2004) Letters to Beall and Priest. In G. Priest, J.C. Beall, and B. Armour-Gard (eds) The Law of Non-Contradiction: New Philosophical Essays. Oxford: Oxford University Press, pp. 176-177.

Linsky, B. and Zalta, E.N. (1991) Is Lewis A Meinongian? Australasian Journal of Philosophy 69(4): 438-453.

McMichael, A and Zalta, E. (1980) An Alternative Theory of Nonexistent Objects. Journal of Philosophical Logic 9: 297-313.

Meinong, A. (1915/1972) Über Möglichkeit und Wahrscheinlichkeit: Beiträge zur Gegenstandstheorie und Erkennntnistheorie. Volume VI of Alexius Meinong, Gesamtausgabe. Originally published by Johann Ambrosius Barth in Leipzig, 1915; reprinted by Akademische Druck - u. Verlagsanstalt, Graz, 1972. Page references are to the 1972 edition.

Nolan, D. (2007) A Consistent Reading of 'Sylvan's Box'. The Philosophical Quarterly 57(229): 667-673.

Australasian Journal of Logic (15:2) 2018 Article no. 2.4 
Nolan, D. (2015) Personification and Impossible Fictions.British Journal of Aesthetics 55(1): 57-69.

Parsons, T. (1975) A Meinongian Analysis of Fictional Objects. Grazer Philosophische Studien 1: 73-86.

Parsons, T. (1979a) Referring to Nonexistent Objects. Theory and Decision 11: 95-110.

Parsons, T. (1979b) The Methodology of Nonexistence. Journal of Philosophy 76(11): 649662.

Parsons, T. (1980) Nonexistent Objects. New Haven and London: Yale University Press.

Penrose, L.S. and Penrose, R. (1958) Impossible Objects: a Special Type of Visual Illusion. The British Journal of Psychology 49(1): 31-33.

Priest, G. (1979) The Logic of Paradox. Journal of Philosophical Logic 8(2): 219-241.

Priest, G. (1992) What is a Non-Normal World? Logique et analyse 35: 291-302.

Priest, G. (1997) Sylvan's Box: a Short Story and Ten Morals. Notre Dame Journal of Formal Logic 38(4): 573-582.

Priest, G. (2008) The Closing of the Mind: How the Particular Quantifier became Existentially Loaded behind our Backs. The Review of Symbolic Logic 1(1): 42-55.

Priest, G. (2011) Against Against Nonbeing. The Review of Symbolic Logic 4(2): 237-253.

Priest, G. (2016a) Towards Non-Being, 2nd edition. Oxford: Oxford University Press.

Priest, G. (2016b) Thinking the Impossible. Philosophical Studies 173(10): 2649-2662.

Proudfoot, D. (2006) Possible Worlds Semantics and Fiction. Journal of Philosophical Logic 35(1): 9-40.

Routley, R. (1979) The Semantical Structure of Fictional Discourse. Poetics 8(1): 3-30.

Routley, R. (1980) Exploring Meinong's Jungle and Beyond: An Investigation of Noneism and the Theory of Items (Interim edition). Departmental Monograph No. 3, Philosophy Department, Research School of Social Sciences, Australian National University, Canberra.

Russell, B. (1905) Critical Notice of Untersuchungen zur Gegenstandstheorie und Psychologie. Mit Unterstützung des k.k. Ministeriums für Kultus und Unterricht in Wien herausgegeben, by A. Meinong. Mind, n.s. 14(56): 530-538.

Smiley, T. (1993) Can Contradictions be True? Proceedings of the Aristotelian Society, Supplementary Volume 67: 17-33.

Swain, S., Alexander, J., Weinberg, J. M. (2008) The Instability of Philosophical Intuitions: Running Hot and Cold on Truetemp. Philosophy and Phenomenological Research 76(1): 138-155.

Wilkes, K.V. (1988) Real People: Personal Identity without Thought Experiments. Oxford: Clarendon Press.

Australasian Journal of Logic (15:2) 2018 Article no. 2.4 
Zalta, E.N. (1986) Lambert, Mally, and the Principle of Independence. Grazer Philosophische Studien 25/26: 447-459.

Zalta, E. N. (1988) Intensional Logic and the Metaphysics of Intentionality. Cambridge, MA: MIT Press.

Zalta, E.N. (1997) A Classically-Based Theory of Impossible Worlds. Notre Dame Journal of Formal Logic 38(4): 640-660.

Zalta, E.N. (2010). In Defense of the Law of Non-Contradiction. In G. Priest, J.C. Beall, B. Armour-Garb (eds) The Law of Noncontradiction: New Philosophical Essays. Oxford: Oxford University Press.

Australasian Journal of Logic (15:2) 2018 Article no. 2.4 


\section{Notes}

${ }^{1}$ Noneists tend to distinguish themselves from the historical Meinong, since they reject Meinong's claim that abstract objects subsist (see e.g. Priest 2016a, p. xviii). In this paper I ignore Meinong's distinction between existence and subsistence, and so I treat 'Meinongian' and 'noneist' alike (this has no impact on the discussion). I also do not mean to imply that Meinong himself proposed a 'Meinongian' theory, either of fiction or more generally.

${ }^{2}$ Richard Hanley claims that inventing counterexamples is 'much harder than you might think' (2004, p. 120). Indeed he claims that 'this employment of thought experiment, telling a short fiction about a non-existent fiction, is bound to fail'. This is, he says, because the proponent of the semantics of fictional discourse that is under attack 'can simply deny the interpretation' of the invented (or extant) fiction that creates the problem for his or her theory (ibid., p. 119). For example, Hanley denies that Graham Priest's story 'Sylvan's Box' contains a genuine contradiction; in Hanley's view, it is merely a consistent story told by an unreliable narrator. Constructing impossible counterexamples can at most, then, lead to a standoff, Hanley says: 'Priest can of course retort that my reaction is theory-driven, but I will say exactly the same of him. We preach to our respective choirs' (ibid., p. 125). If Hanley is correct, the CEP is not much of a problem. However, Hanley's claim is unconvincing. To deny a problematic interpretation, the semanticist needs some independent reason. For example, Hanley's own account of 'Sylvan's Box' is implausible; it neglects the fact that genuine unreliable-narrator fictions are signalled as such (well-known examples are Fight Club, The Turn of the Screw, and Lolita, all of which have features undermining the narration). It is not enough to make a narrator unreliable that the tale he or she narrates is impossible - this might be so in reality, but it is not so in fiction.

${ }^{3}$ It follows that my use of the expression 'intuition' and its cognates is merely something like 'a verbal tick' (as Herman Cappelen puts it (2012, p. 22)).

${ }^{4}$ For example, Zalta appealed to intuitions in McMichael and Zalta 1980 and Linksy and Zalta 1991. Parsons remarked that ' $[\mathrm{w}]$ hether or not something is true in a story ought to accord with what a normal attentive reader understands to be true in the story' (1980, p. 175). In 'Sylvan's Box: a Short Story and Ten Morals', Priest sets what he calls 'an old-fashioned comprehension test on the story'; in this (and in the answers he gives) he is also describing what a normal attentive reader would understand to be true in the story (1997, p. 579).

${ }^{5}$ Nolan suggests that we might 'not need to generalize to fiction in general' from merely invented counterexamples (2015, pp. 60-61).

${ }^{6}$ The novel is by Walter Abish, and John Updike called it 'delightful' in his review in The New Yorker (March 24, 1974, p. 112).

${ }^{7}$ The collective belief worlds of the community of origin of $f$ are all those worlds where the overt beliefs of the community - those beliefs which 'more or less everyone shares ... [and] more or less everyone thinks that more or less everyone else shares' (Lewis 1983, p. 272) - are true. The account quoted in the text is Lewis's 'Analysis 2'; he also offered Analysis 1, where the benchmark is not the collective belief worlds of the community of origin of $f$, but rather the actual world. The choice of analysis is left to taste. All references in this paper to Lewis's analysis should be understood as applying to both Analyses.

${ }^{8}$ Jasper Fforde, The Fourth Bear (Hodder and Stoughton, 2006), pp. 14-15.

${ }^{9}$ It has been argued that it is metaphysically impossible that $x$ can be both actual and fictional. Kripke (1980, pp. 156-158) and Kaplan (1973, pp. 505-508) have argued that, where $x$ is a fictional character, there is no possible world in which $x$ exists; a fortiori, $x$ cannot exist in the actual world, and so $x$ cannot be both actual and fictional. In this paper I assume the stronger sense of impossibility, i.e. logical impossibility.

${ }^{10}$ On the 2001 paperback published by Hodder and Stoughton in the UK.

${ }^{11}$ In any case, if it is not agreed that ' $x$ is both actual and (purely) fictional' entails a contradiction, a different fiction and contradiction-entailing root can simply be offered, for example Alice's Adventures in Wonderland and 'The Cheshire Cat vanished while its grin remained'.

${ }^{12}$ Taken from the Penguin 2003 US publication. 
${ }^{13}$ In a 2001 letter to Graham Priest, Lewis said 'I'm increasingly convinced that I can and do reason about impossible situations. ("Sylvan's Box" played a big part in persuading me.)'; and he mentioned (without further elaboration) a 'similarity metric' for 'possibilities together with impossibilities' (Lewis 2004, pp. 176, 177). Unfortunately, these brief remarks do not suggest another way for the possible worlds semanticist to deal with impossible fictions. For Lewis went on to say, "what I find myself doing is reasoning about subtly impossible situations, and rejecting suppositions that lead fairly to blatant impossibilities' (ibid., p. 176). The fictions that I consider in this article contain blatant (though not explosive) impossibilities, some of which are impossible (though true) even in the fiction.

${ }^{14}$ Aeschylus wins by 'threw[ing] two chariots and two corpses in'. (Aristophanes, The Frogs, in C.W. Eliot (ed.) Nine Greek Dramas by Aeschylus, Sophocles, Euripides and Aristophanes, Vol. VIII. Harvard Classics, 1909, pp. 462-3.)

${ }^{15} \mathrm{Or}$ if it is a property 'naturally represented in the predicate calculus as a predicate appropriate to concrete objects' (Parsons 1979b, p. 659). Parsons (e.g. 1980) lists other sufficient conditions.

${ }^{16} \mathrm{Or}$ if it is denoted by a predicate that has aroused philosophical 'controversy' (Parsons 1979a, p. 102).

${ }^{17}$ See also Linsky and Zalta 1991, p. 443. Zalta also extended the logic of encoding to states of affairs or worlds, in addition to objects, to produce what he calls 'impossible worlds'; these worlds encode but do not exemplify contradictory properties (1997, p. 651; see also Zalta 2010). Zalta claimed that his impossible worlds are 'genuine impossible worlds, and not ... ersatz worlds' (1997, p. 640).

${ }^{18}$ On Parsons' account, fictional objects are individuated in terms of nuclear properties. Where $s$ is a particular story (or stories) and ' $\phi$ ' is either a description or a name:

The $\phi$ of $s=$ the object $x$ which is such that for any nuclear property $p, x$ has $p$ if, and only if, the $\phi$ of $s$ is such that in $s$ it has $p$. (Parsons 1980, p. 55)

${ }^{19}$ According to Meinong, 'die sogenannte Tatsächlichkeit eines runden Viereckes nichts wieter ist, als was ich oben die depotenzierte' (1915/1972, p. 291).

${ }^{20}$ This formulation is to suit Parsons' emphasis on properties. For Meinong, it is the state of affairs, the round square's existing, that has watered-down (vs full-strength) being.

${ }^{21}$ See Parsons 1980, p. 44 for the application to existence.

${ }^{22}$ One response to this counterexample (independently suggested by a reviewer for the $A J L$ ) would be to introduce new properties, encoding $F$ and exemplifying $F$. Zalta's theory would then produce two fictional objects: one encodes the encoding of squareness and non-squareness and the other encodes the exemplifying of squareness and non-squareness. However (and irrespective of questions about the nature of such secondorder properties), we could frustrate this fix by means of yet other hypothetical fictions, according to which the distinction between two objects is precisely that one exemplifies the encoding (exemplifying) of $F$ whereas the other merely encodes the encoding (exemplifying) of $F$. The fix just suggested would not enable Zalta's theory to capture this distinction.

${ }^{23}$ In his 2001 letter to Priest, as in his 'Postscript to "Truth in Fiction", Lewis alluded to make-believe. He said that sometimes he made believe 'that impossibilities are possible, subtle ones at least', and he agreed with Priest about 'the many uses to which we could put make-believedly possible impossibilities' (Lewis 2004, p. 177). Introducing the notion of make-believe allows the possible worlds semanticist to say that the fiction-writer and reader merely make believe that there are worlds where some contradictions are true, and this gives room - if only in principle - for a possible worlds analysis of intra-fictional truths about impossible fictions. The analysis of merely make-believe contradictions, however, would have to be invulnerable to the sort of counterexample targeted against Parsons's and Zalta's merely impossible objects.

${ }^{24}$ Priest uses the expression 'logically impossible possible world' in Priest 1992 (p. 292).

${ }^{25}$ This response, strictly speaking, is addressed to criticisms of the noneists' treatment, not of the logical connectives, but of 'unloaded' quantification (i.e., to their claim that the quantifiers $\forall$ and $\exists$ are 'existentially neutral', to be understood only as 'every' and 'some' (Priest 2016a, p. xviii)).

${ }^{26}$ Thus, Priest says:

Australasian Journal of Logic (15:2) 2018 Article no. 2.4 
[W]hen I meet people who (at least claim to) find unloaded quantification unintelligible, I am tempted to reply as did the Australian philosopher Brian Medlin on one occasion when, in its early years, he was advocating the mind-brain identity theory. Someone objected (?) 'I just don't understand what it would be for a mental process to be an inch behind your left eye'; he replied 'Get yer understander re-wired.' (2008, p. 43).

${ }^{27}$ In Proudfoot 2006 I claimed that most actual fictions are 'bounded': a fiction is bounded just if there are areas (of space or time) beyond which it says nothing. Boundedness can also be logical. Just as theories of truth in fiction need to accommodate the spatio-temporal boundedness of a fiction, so they need to accommodate its logical boundedness.

${ }^{28}$ Nor is 'Sylvan's Bottle' anything like this.

${ }^{29}$ Someone did say this - an anonymous AJL reviewer, to whom I am indebted.

${ }^{30}$ See Routley 1979, p. 10.

${ }^{31}$ In Proudfoot 2006 I called this the distinction between 'realistic' and 'surrealistic' fantasy. These terms have a variety of uses, however, so I have renamed the distinction. Hanley (see Note 3) invokes a 'consistency constraint' that prevents us from interpreting any supposedly 'impossible' fiction as genuinely contradictory (2004, p. 123). In my view, this ignores the distinctions between inconsistent and paradoxical fictions and also between IFP and IFI fictions.

${ }^{32}$ Escher said that he 'discovered the principle' of the staircase in 'Ascending and Descending' in the Penroses' paper (M.C. Escher, in a letter of 24 January 1960 to his son Baarn, quoted in Bool et al. 1992, p. 99). The Penroses had described a figure as lines 'connected in such a manner as to produce an impossibility' (Penrose and Penrose 1958, p. 31).

${ }^{33}$ M.C. Escher, in a letter of 21 October 1956 to his brother Erich, quoted in Bool et al. 1992, pp. 86, 87.

${ }^{34}$ M.C. Escher, in a 1963 lecture in Hilversum in the Netherlands, quoted in Bool et al. 1992, p. 147.

${ }^{35}$ M.C. Escher, in a 1963 lecture in Hilversum in the Netherlands, quoted in Bool et al. 1992, p. 147.

${ }^{36}$ My italics.

${ }^{37}$ I do not mean to imply that an 'inconsistent' fiction coincides with an IFP fiction (or that a 'paradoxical' fiction coincides with an IFI fiction). Although this may often be true, restricting the fiction-writer's options in this way would violate Routley's Thesis.

${ }^{38}$ The logic is S5.

${ }^{39} \mathrm{I}$ am indebted to an anonymous reviewer for the AJL, who suggested this approach. 